\title{
Sustainable Autarky of Food-Energy-Water
}

\author{
S.M. Henkanatte-Gedera, T. Selvaratnam, N. Nirmalakhandan* \\ Civil Engineering Department, New Mexico State University, Las Cruces, NM 88003, USA
}

\begin{abstract}
Meeting the demand for food, energy, and water to sustain the worldwide growth of urban population is a major challenge. Several recent reports have concluded that one approach to overcome this challenge is to recover and recycle resources within the food-energywater (FEW) nexus in urban settings. Urban wastewaters (UWW) are now being recognized as a resource, rich in nutrients and energy, rather than a waste stream that has to be treated and disposed of at the expense of significant energy input and associated environmental emissions. Reclaiming reusable water, nutrients, and energy from UWWs can contribute to autarky of FEW nexus and render the wastewater management process sustainable and potentially profitable. This paper presents a novel approach to treat UWW with the potential for high recovery of energy, nutrients, and water from UWW for use in food crop production. This approach entails cultivation of energy-rich algal biomass in primary-settled UWW followed by extraction of biocrude and nutrients from the algal biomass by hydrothermal liquefaction. A fraction of the recovered nutrients is recycled to boost biomass production while the rest can be stockpiled for use as fertilizer. Results from a pilot scale field study conducted at a local wastewater treatment plant confirmed that the algal system can achieve $>80 \%$ removal of organic carbon, ammoniacal-nitrogen, and phosphates in UWW, meeting the respective discharge standards in a single step, with a batch process time of three days.
\end{abstract}

Keywords: Wastewater, energy recovery, nutrient recovery, algal cultivation

\section{Introduction}

Food, energy, and water (FEW) have long remained vital needs for human well-being and civilization. Following the industrial and agricultural revolutions, FEW needs of the growing populations have been met by highly centralized and mechanized FEW infrastructure systems. The rapid transition from the natural infrastructure (e.g. rain-fed agriculture) to the engineered infrastructure (e.g. pumped groundwater irrigation) has led to scarcities and insecurities due to pollution (e.g. runoff), resource degradation (e.g. groundwater depletion), and external drivers (e.g. climate change). It is now acknowledged that the technologies embedded in current FEW infrastructure systems are not sustainable because of their heavy reliance on non-renewable resources (e.g. fossil fuel, phosphorous) and their long-lasting ecological impacts (e.g. global warming, eutrophication). For example, over the last 25 years, the world economy has quadrupled, while $60 \%$ of the world's major ecosystem goods and services have been degraded or used unsustainably [1].

With nearly $70 \%$ of the world population already concentrated in towns and cities, and with continuing trends in population growth and sprawl of metropolitan areas, provision of the basic human needs of food, energy, and water to the urban inhabitants is seen as a major challenge. Being net consumers of food, energy, and water, current urban infrastructure that continues to rely on obsolete technologies to provide these basic needs is not sustainable. Development of innovative infrastructure that can recover and recycle energy and materials within the foodenergy-water (FEW) sectors of urban environments could be one of the options to improve the sustainability of urban and agricultural systems.

Intensifying production to meet the FEW needs of growing populations with limited resources is a challenging task because the FEW techno-sectors are interrelated and interdependent, in space and time, directly and indirectly, in complex manners. Many agencies now agree that a sustainable autarky in these sectors could be achieved taking advantage of synergies and addressing tradeoffs in the FEW nexus for sustainable intensification to balance growing demand and declining resources. Some options for improving sustainability include decoupling economic development from resource utilization; maximizing resource use efficiency; and minimizing impacts on the ecosphere. Using biofuels generated from waste streams and renewable feedstock to augment fossil fuels, for example, is one way to decouple economic development from resource utilization, maximize resource use efficiency, and minimize

${ }^{*}$ Corresponding author. Tel.: +15756465378

E-mail: nkhandan@nmsu.edu

(C) 2017 International Association for Sharing Knowledge and Sustainability

DOI: $10.5383 /$ ijtee.14.02.001 
ecological impacts. Past research and practice in the FEW sectors had focused on improving productivities to achieve sector-specific optima; to improve sustainability in these sectors, it is necessary to go beyond sectorial performance and strive towards system efficiency through technological innovations and tradeoffs.

This paper presents an algal-based, photosynthetically oxygenated waste-to-energy recovery (POWER) process for recovering energy, water, and nutrients from urban wastewaters (UWW) for use in the food production sector. By recovering and recycling resources within urban/agricultural systems, and harvesting net energy from the wastewater, the POWER process has the potential for achieving sustainable autarky in the FEW nexus.

\section{The POWER Process}

Urban wastewaters (UWW) are now being recognized as a resource, rich in nutrients and energy, rather than a waste stream that has to be treated and disposed of at the expense of significant energy input and associated environmental emissions. Traditional wastewater treatment plants employ a series of processes, each designed to remove a target constituent of UWW: suspended solids by primary processes; dissolved organics by secondary processes; nutrients by biological nutrient removal processes; and, pathogens by disinfection processes. As they remove their target constituents from the wastewater, most of these processes consume significant fossil fuel-derived energy. For example, energy consumption by traditional wastewater treatment technologies has been reported to be 1.48 kW-hr per kg of Biological Oxygen Demand (BOD) removal; $13.44 \mathrm{~kW}$-hr per kg nitrogen $(\mathrm{N})$ removal; and $6.44 \mathrm{~kW}$-hr per $\mathrm{kg}$ phosphate $(\mathrm{P})$ removal [2]. On average, power consumption for aeration in the activated sludge process averages $0.3 \mathrm{~kW}$-hr per cu $\mathrm{m}(\sim 1 \mathrm{~kJ} / \mathrm{L})$ of wastewater treated [3]. Emissions associated with the energy demand for wastewater treatment in the US have been estimated as 15.5 teragrams (Tg) CO2equivalents, an acidification potential of 145 gigagrams (Gg) SO2 equivalents, and eutrophication potential of $4 \mathrm{Gg}$ PO43equivalents [4]. As such, the traditional UWW treatment technologies are seen as unsustainable.

While the focus of traditional UWW treatment practice had been to meet discharge standards for effluent and stabilize the solids generated during treatment, current research is focused on minimizing energy consumption in UWW treatment and recovering energy from the wastewater as well as the solids. The POWER process developed in this study affords UWW treatment, net energy production, and recovery of irrigationquality water and high-purity crop fertilizers. The strain used in the POWER process is Galdieria sulphuraria, capable of heterotrophic growth under elevated temperatures of $25-56^{\circ} \mathrm{C}$ and low $\mathrm{pH}$ of 0.9 to 4 [5]. The POWER process enables singlestep removal of carbon (BOD) and nutrients such as nitrogen (N) and phosphates (P) from UWWs through heterotrophic metabolism. Specific advantage of this system over the traditional heterotrophic bacteria-based activated sludge process stems from the fact that stoichiometric carbon-to-nitrogen (C:N) ratio in UWW is closer to that of algal biomass composition than to that of heterotrophic bacteria. As such, the proposed algal system is capable of incorporating all the $\mathrm{C}, \mathrm{N}$, and $\mathrm{P}$ in $\mathrm{UWW}$ into biomass without any energy input and without any loss of $\mathrm{C}$ as $\mathrm{CO} 2$ as in the current activated sludge process. Another advantage of the POWER process is that it conserves the energy currently being expended in the activated sludge process for oxidizing BOD. In addition, solar energy captured by the
POWER process via photosynthesis is also incorporated into the algal biomass.

The energy-rich biomass cultivated in the wastewater is then hydrothermally processed in the POWER process to yield four product streams- biocrude, biochar, an aqueous phase, and offgases. A large fraction of the energy in the algal biomass is recovered as biocrude and biochar; while most of the $\mathrm{N}$ in the algal biomass is solubilized in the aqueous phase for recovery and reuse as fertilizers; the $\mathrm{P}$ in the biomass is concentrated in the biochar, which can be used as a soil amendment or processed to extract the $\mathrm{P}$ for use in fertilizer formulation. Since the hydrothermal process is operated at $200-300$ oC, its products can be used in crop production with minimal risks. Salient features of the traditional wastewater treatment system and those of the POWER process are compared in Figure 1.
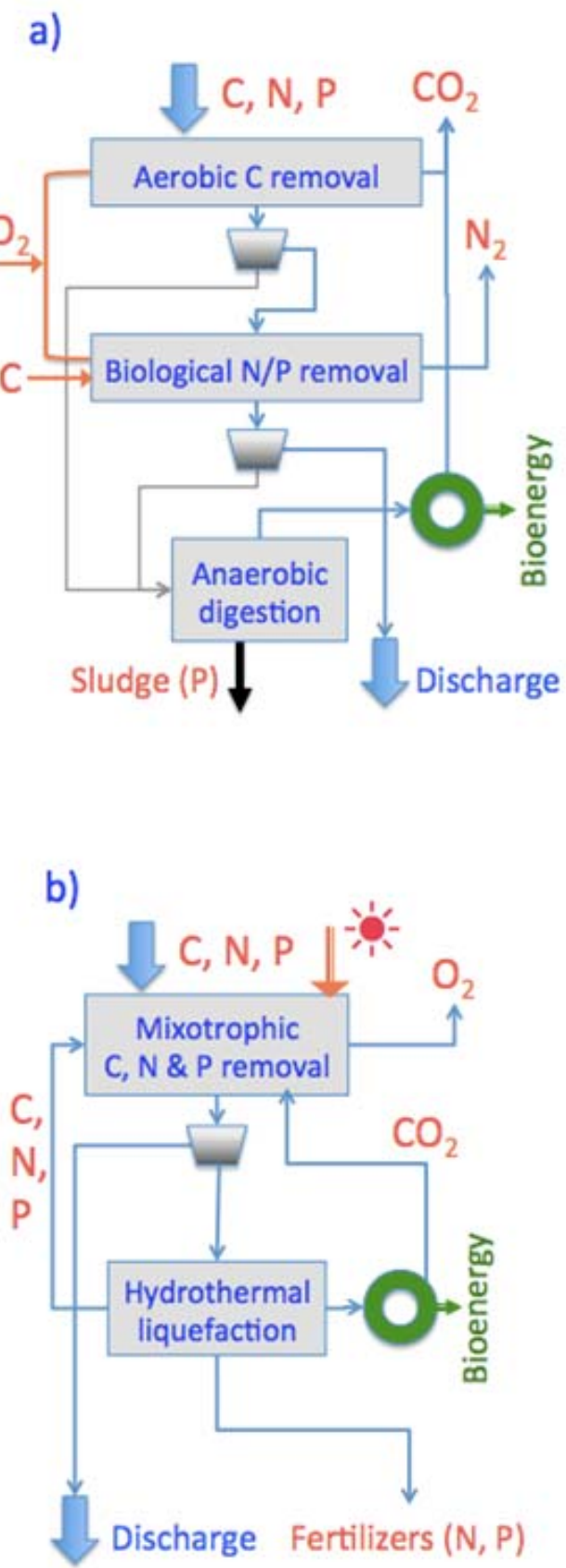

Figure 1. Salient features of traditional wastewater treatment process (a) and the POWER process (b). 


\section{Materials and Methods}

The POWER process has been validated under laboratory conditions and under field conditions at a local wastewater treatment plant [6-10]. The laboratory studies evaluated the ability of Galdieria sulphuraria in growing in sterilized primary settled wastewater collected from the local wastewater treatment plant. These tests were conducted in 6-mL batch reactors under artificial light and controlled environment.

Based on the promising results from the laboratory tests, a pilot scale system was developed to validate the POWER process under field conditions. The pilot scale cultivation system is based on the traditional raceway configuration but incorporated a low-cost, enclosed photobioreactor (PBR) fabricated out of transparent polyethylene tube (of diameter $=1.83 \mathrm{~m}$; and wall thickness $=10 \mathrm{~mm}$ ) as shown schematically in Figure 2.

This enclosed PBR design circumvented several of the drawbacks of the traditional, open raceway configuration: odor emissions, evaporative water losses, potential for invasion and contamination; and loss of $\mathrm{CO}_{2}$ [11]. Due to the thermophilic nature of Galdieria sulphuraria this PBR configuration does not require any cooling. Culture temperatures typically ranged 31 $50{ }^{\circ} \mathrm{C}$.

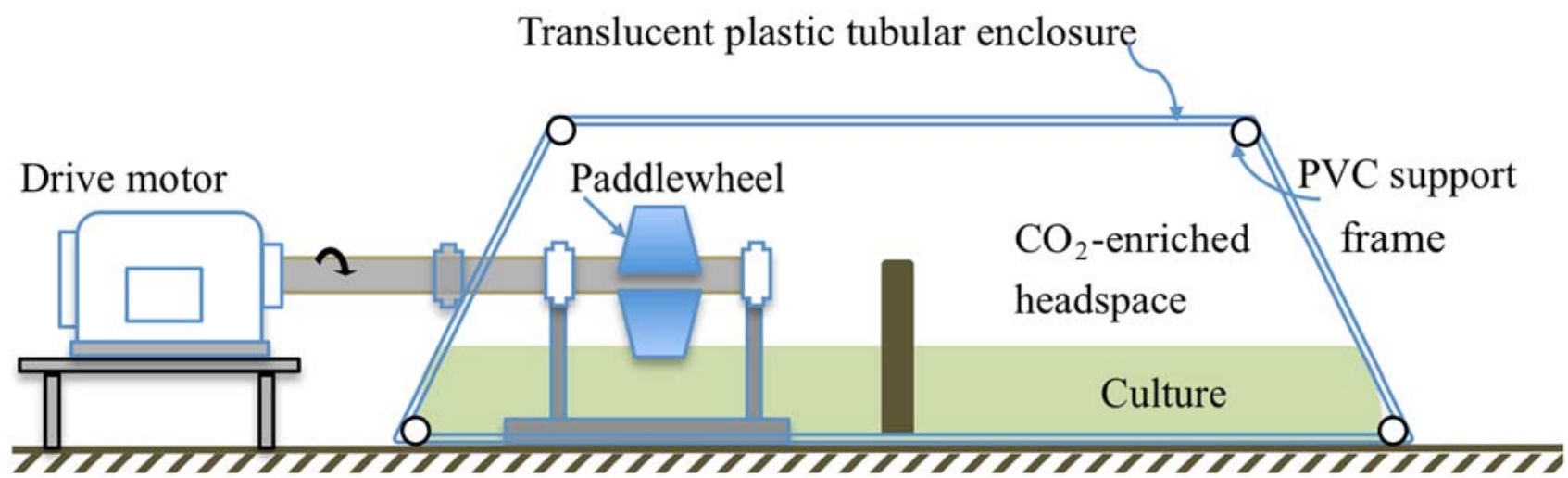

Figure 2. Schematic of the enclosed photobioreactor developed for the POWER process.
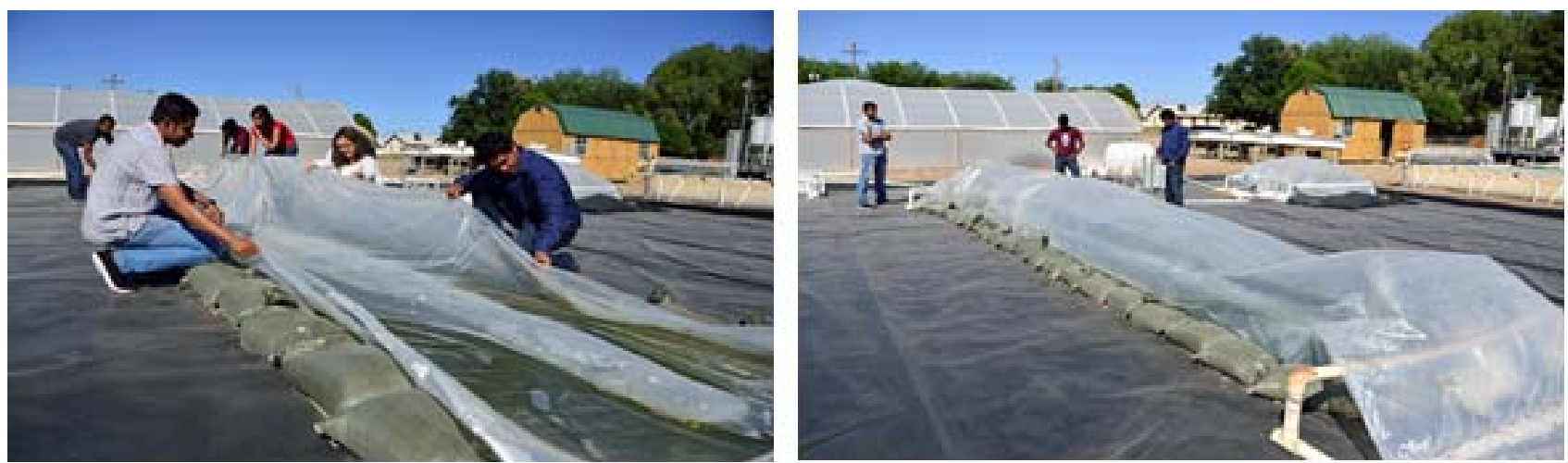

Figure 3. Fabrication of the enclosed photobioreactor for cultivating Galdieria sulphuraria in the POWER process.

The pilot scale system was fed with primary effluent, whose dissolved BOD 5 ranged from 40 to $60 \mathrm{mg} / \mathrm{L} ; \mathrm{NH}_{4}-\mathrm{N}$ ranged from $35-40 \mathrm{mg} / \mathrm{L}$; and $\mathrm{P}$ ranged from 6 to $8 \mathrm{mg} / \mathrm{L}$. This PBR design was tested at two scales- one at 300-L scale and one at 700-L scale. The cultures were kept in circulation by a paddle wheel system, driven by a $0.2 \mathrm{~kW}$ electric motor. Figure 3 shows the fabrication of the enclosed PBR; Figure 4 shows the field installation of the 700-L PBRs at the local municipal wastewater treatment plant.

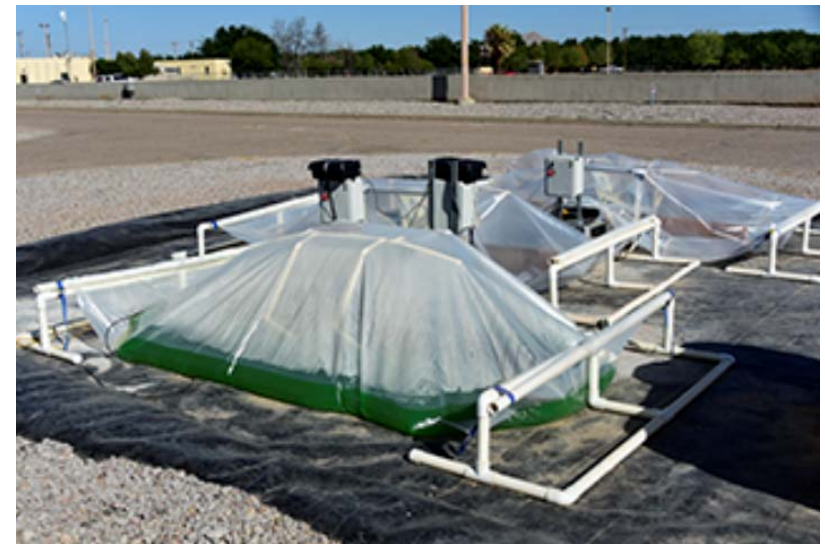

Figure 4. Field installation of the 700-L enclosed photobioreactors at the local wastewater treatment plant. 


\section{Results}

Tests conducted under laboratory conditions and field conditions confirmed that Galdieria sulphuraria is able to grow in primary settled UWW.

Growth and nutrient uptake rates found under laboratory conditions with primary settled wastewater were comparable to or better than those found with the standard artificial growth medium. Nutrient removal rates by Galdieria sulphuraria were found to be higher than those reported in the literature for other algal strains. The removal rate of BOD by Galdieria sulphuraria is also higher than that reported for the traditional activated sludge process.

Hydrothermal liquefaction studies on the algal biomass cultivated in these tests showed that biocrude yield of $22 \%$ could be attained with a net energy ratio of 1.25. Laboratory studies also confirmed that Galdieria sulphuraria could grow in the aqueous phase recycled from the hydrothermal liquefaction process without causing any inhibition. Net energy yield estimated from these laboratory studies confirmed that this process can be potentially more energy efficient than mainstream anaerobic processing (3.6 kJ/L vs. $2.16 \mathrm{~kJ} / \mathrm{L})$. Results from the laboratory tests are summarized in Table 1.

Table 1. Summary of results from laboratory tests on Galdieria sulphuraria (GS).

\begin{tabular}{ll}
\hline Test & Results \\
\hline Mixotrophic growth & Max. density of $2.7 \mathrm{~g} / \mathrm{L}$ in UWW \\
of $G S$ in UWW & vs. $1.6 \mathrm{~g} / \mathrm{L}$ in std. growth medium \\
N-removal from & Removal rate of $8.02 \mathrm{mg} / \mathrm{L}-\mathrm{d}$ \\
UWW by $G S$ & vs. ave. of $6.36 \mathrm{mg} / \mathrm{L}-\mathrm{d}$ in literature \\
P-removal from & Removal rate of $1.69 \mathrm{mg} / \mathrm{L}-\mathrm{d}$ \\
UWW by $G S$ & vs. ave. of $1.34 \mathrm{mg} / \mathrm{L}-\mathrm{d}$ in literature \\
BOD-removal from & $1^{\text {st } \text { order rate of } 0.71 / \mathrm{d} \text { vs. ave. }}$ \\
UWW by $G S$ & of $0.291 / \mathrm{d}$ for aerobic process \\
Biocrude yield by & Optimum yield of $22 \%$ @ $275^{\circ} \mathrm{C}$ with \\
HTL of $G S$ & net energy ratio of 1.25 \\
Growth of $G S$ in & Growth rate of $0.18 \mathrm{~g} / \mathrm{L}-\mathrm{d}$ \\
recycled AP of HTL & vs. $0.134 \mathrm{~g} / \mathrm{L}-\mathrm{d} \mathrm{in} \mathrm{std} . \mathrm{medium}$ \\
Net energy yield via & Estimated $3.6 \mathrm{~kJ} / \mathrm{L} \mathrm{vs.} 2.16 \mathrm{~kJ} / \mathrm{L}$ \\
HTL of $G S$ & by McCarty et al $(2011)$ \\
\hline
\end{tabular}

The pilot scale studies at the local wastewater treatment plant have been on-going for the past one year. This pilot scale system is fed with primary effluent, after adjusting the $\mathrm{pH}$ to 3.0.

Typical results from the tests conducted at the local wastewater treatment plant in batch mode ( $3 \times 700$-L photobioreactors) are shown in Figure 5. As can be seen from these results, the POWER process was able to remove BOD, $\mathrm{N}$, and $\mathrm{P}$ from the primary-settled wastewater to the respective discharge levels in a batch processing time of about three days.
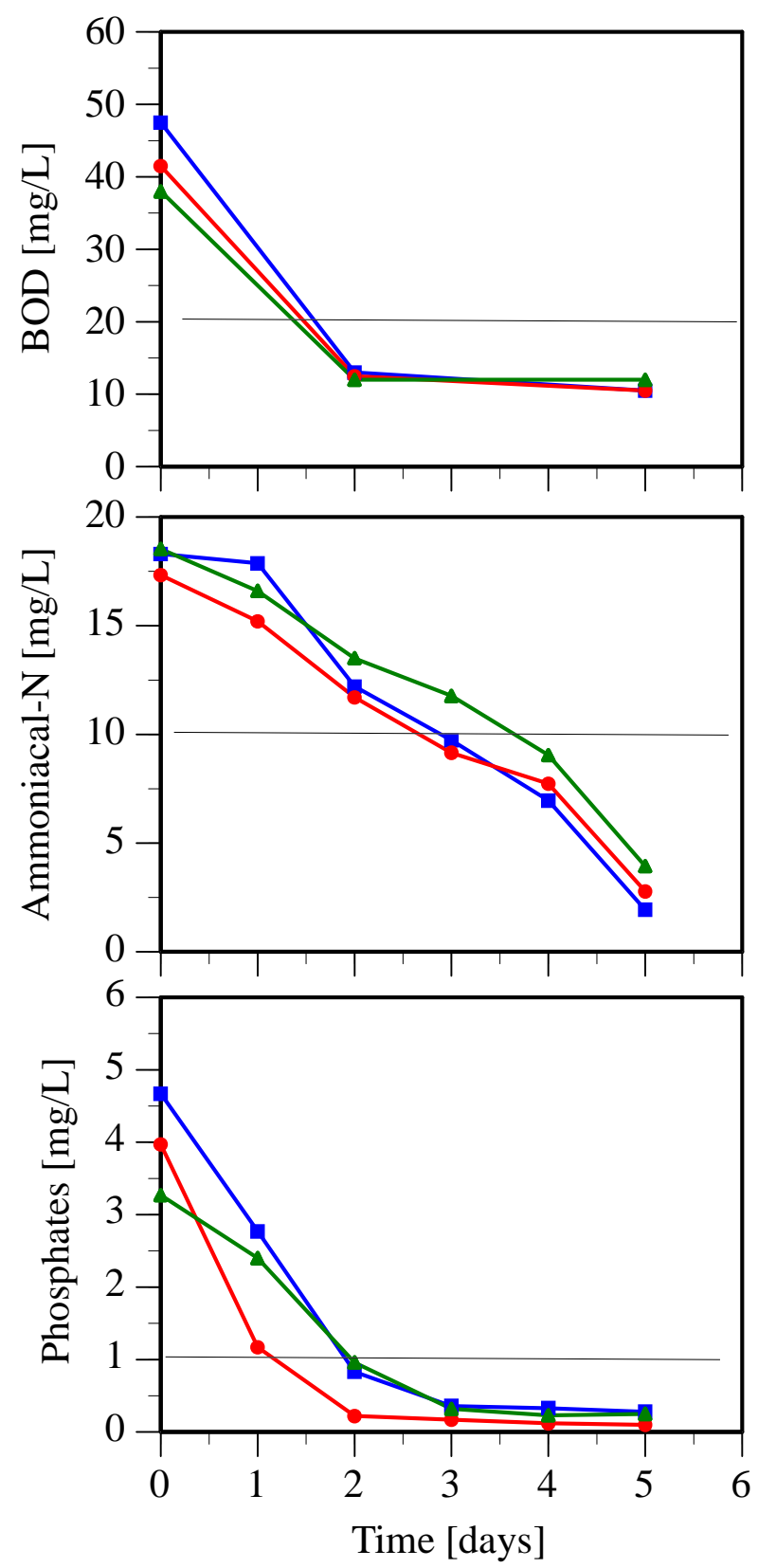

Figure 5. Typical removal of BOD, ammoniacal-N, and $P$ from primary settled wastewater by the POWER process under field tests in three identical reactors. Horizontal lines represent discharge standards.

These tests confirmed that Galdieria sulphuraria could utilize organic carbon in the wastewater as a growth substrate, making it a feasible strain for removing BOD, N, and P from UWW in a single step with minimal energy input. The POWER process can be seen to be advantageous over the current and other emerging technologies in removing nutrients from UWW and recovering them for beneficial use. 
For example, in the traditional tertiary treatment by nitrificationdenitrification [12] or in emerging technologies such as aerobic deammonification process [13], CANON process [12], and DEAMOX process [14], valuable $\mathrm{N}$ is dissipated into the environment; whereas, the POWER process affords an efficient pathway to recover $\mathrm{N}$ from the aqueous phase generated by the hydrothermal process for use as fertilizers. In the above experiments, $\mathrm{N}$-levels in the aqueous phase ranged 3,500 -5,000 $\mathrm{mg} / \mathrm{L}$. Similarly, a large fraction of the P released from the biomass by hydrothermal liquefaction is concentrated in the biochar at $75,000 \mathrm{mg} / \mathrm{kg}$. As such, the byproducts of hydrothermal processing of the algal biomass can be potentially processed further to formulate fertilizers by struvite precipitation.

\section{Conclusions}

This paper presented a novel algal-based approach for treating the wastewaters to the mandated discharge levels and maximizing the recovery of energy and nutrients from the wastewater for possible use as crop fertilizers. The proposed approach has the potential to not only meet the mandated wastewater treatment standards, but also to abate harmful emissions to the environment, and enable high degree of recycling and reusing limited natural resources to improve to sustainability of food-water-energy sectors.

\section{Acknowledgments}

This study was supported in part by the NSF Engineering Research Center for Reinventing the Nation's Urban Water Infrastructure (ReNUWIt) award \# EEC 1028968; the US Department of Energy under contract DE-EE0003046 to the National Alliance for Advanced Biofuels and Bioproducts (NAABB) and DE-EE0006269 for the Regional Algal Feedstock Testbed Partnership; the National Science Foundation award \#IIA-1301346 (New Mexico EPSCoR); the Office of the Vice President for Research at NMSU; and the Ed \& Harold Foreman Endowed Chair.

\section{References}

[1] "UNDP, 2011, Towards a Green Economy: Pathways to Sustainable Development and Poverty Eradication," ed: United Nations Environment Program, 2011.

[2] S. J. Kang, K. Olmstead, K. Takacs, and J. Collins, "Municipal Nutrient Removal Technologies Reference Document, (EPA 832-R-08-006)," EPA 832-R-08-006, 2008.

[3] P. L. McCarty, J. Bae, and J. Kim, "Domestic Wastewater Treatment as a Net Energy Producer-Can This be Achieved?," Environmental Science \& Technology, vol. 45, pp. 7100-7106, Sep 2011.
[4] EPA, "Inventory of U.S. Greenhouse Gas Emissions and Sinks: 1990-2012," EPA 430-R-14-003, 2014.

[5] J. A. Toplin, T. B. Norris, C. R. Lehr, T. R. McDermott, and R. W. Castenholz, "Biogeographic and phylogenetic diversity of thermoacidophilic Cyanidiales in Yellowstone National Park, Japan, and New Zealand," Applied and Environmental Microbiology, vol. 74, pp. 2822-2833, May 2008.

[6] T. Selvaratnam, S. M. Henkanatte-Gedera, T. Muppaneni, N. Nirmalakhandan, S. Deng, and P. J. Lammers, "Maximizing recovery of energy and nutrients from urban wastewaters," Energy, vol. 104, pp. 16-23, 6/1/ 2016.

[7] T. Selvaratnam, H. Reddy, T. Muppaneni, F. O. Holguin, N. Nirmalakhandan, P. J. Lammers, et al., "Optimizing energy yields from nutrient recycling using sequential hydrothermal liquefaction with Galdieria sulphuraria," Algal Research, vol. 12, pp. 74-79, 11// 2015.

[8] T. Selvaratnam, A. K. Pegallapati, F. Montelya, G. Rodriguez, N. Nirmalakhandan, W. Van Voorhies, et al., "Evaluation of a thermo-tolerant acidophilic alga, Galdieria sulphuraria, for nutrient removal from urban wastewaters," Bioresource Technology, vol. 156, pp. 395-399, 2014.

[9] T. Selvaratnam, A. K. Pegallapati, H. Reddy, N. Kanapathipillai, N. Nirmalakhandan, S. Deng, et al., "Algal biofuels from urban wastewaters: Maximizing biomass yield using nutrients recycled from hydrothermal processing of biomass," Bioresource Technology, vol. 182, pp. 232-238, 4// 2015.

[10] S. M. Henkanatte-Gedera, T. Selvaratnam, N. Caskan, N. Nirmalakhandan, W. Van Voorhies, and P. J. Lammers, "Algal-based, single-step treatment of urban wastewaters," Bioresource Technology, vol. 189, pp. 273-278, 8// 2015.

[11] W. J. Oswald, H. B. Gotaas, H. F. Ludwig, and V. Lynch, "Algae symbiosis in oxidation ponds: photosynthetic oxygenation," Sewage and Industrial Wastes, vol. 25, pp. 692-705, 1953.

[12] Y.-H. Ahn, "Sustainable nitrogen elimination biotechnologies: A review," Process Biochemistry, vol. 41, pp. 1709-1721, 2006.

[13] M. Musabyimana, "Deammonification Process Kinetics and Inhibition Evaluation," Doctoral Civil Engineering, Virginia Polytechnic Institute and State University, Blacksburg, 2008.

[14] J. M. Ebeling, M. B. Timmons, and J. J. Bisogni, "Engineering analysis of the stoichiometry of photoautotrophic, autotrophic, and heterotrophic removal of ammonia-nitrogen in aquaculture systems," Aquaculture, vol. 257, pp. 346-358, Jun 2006. 